\title{
Effect on Human Volunteers of a Fresh Cheese of Enzymatic Coagulation, with Probiotics and Vegetable Ingredients
}

\section{Ramón De Cangas Morán* and Aldo Hernández Monzón}

Institute of Pharmacy and Food, University of Havana, Cuba

*Corresponding Author: Ramón De Cangas Morán, Institute of Pharmacy and Food, University of Havana, Cuba.

Received: October 29, 2019; Published: November 08, 2019

DOI: $10.31080 /$ ASNH.2019.03.0539

\begin{abstract}
The dairy food group has often been unfairly valued even by health professionals. However, the scientific evidence in favour of its habitual inclusion in the diet is increasingly strong for several reasons including a lower risk of cardiovascular, metabolic and overweight and obesity.

Not all dairy products are the same, it seems that the most interesting, from the point of view of possible physiological benefits, are fermented dairy products, such as yoghurts. Cheeses have a higher fat content than other dairy products and due to the addiction of salt their sodium content is higher and although the evidence suggests that consumption of cheese does not increase cardiovascular or metabolic risk, it may be a food that can be modified to improve its nutritional aspects.

The objective of this study was to elaborate a modified fresh cheese, of enzymatic coagulation, without salt, with addiction of probiotics and a series of vegetable ingredients like raw nut without salt, oregano, rosemary, beta-glucan of oats and sweet paprika and to test it by means of a clinical trial in simple blind in healthy human volunteers, verifying the variations in certain variables as a consequence of its consumption.

The results showed statistically significant improvements in variables such as LDL-cholesterol, triglycerides, glycosylated hemoglobin, body fat percentage and defecatory frequency. Therefore this type of modifications in the cheese can be interesting.

Keywords: Cheese; Enzymatic Coagulation; Hemoglobin
\end{abstract}

\section{Introduction}

It is very common for controversy to arise around the consumption of whole dairy products in terms of cardiovascular and metabolic risk, but the strength of the scientific evidence is increasingly clear that whole dairy products may not be harmful but even beneficial.

First of all we must bear in mind that not all sources of saturated fat are the same. The main food sources of saturated fatty acids are products of animal origin, such as meat and meat products, and dairy products such as butter, cheese, milk and other whole milk products $[1,2]$. Not all saturated fats behave the same and therefore some foods that provide saturated fat may not be harmful from a cardiovascular health point of view or may even be beneficial.

Dairy products, with the exception of butter, appear to be safe with respect to cardiovascular risk and may even contribute to reducing it [3] and fermented dairy products may be especially beneficial, perhaps in part due to probiotics [4].

Some published studies [5] evaluated the effects of cheese (and also meat) as a source of saturated fatty acids by comparing a diet that included such foods with one with the same kilocalories but where that saturated fat was replaced by an extra supply of carbohydrates. Cheese diets raised HDL and Apolipoprotein A1 more 
than the low-fat, carbohydrate-rich version of the diet and also increased bile acid secretion and in the case of cheese there is an increase in faecal fat excretion (something that does not occur in meat).

Other studies [6] conclude that there is no relationship between consumption of whole dairy products and metabolic syndrome, and even suggest that dairy fatty acids may have a protective effect.

\section{Change in strategy?}

If this were so, the dietary strategy of recent years to advise reducing the intake of foods such as whole dairy products in order to reduce the intake of saturated fats and in return to take more carbohydrates (without taking into account the type of carbohydrates) could in some cases be a "nutritional error". Although saturated fats have been denigrated for years, for some time now various studies have been suggesting that the effects of saturated fat on cholesterol and on the risk of cardiovascular disease itself seems to depend on specific saturated fatty acids and their interactions with the matrix in which they are found and its nutritional composition.

One of the reasons why not all sources of saturated fat are the same is that not all fatty acids are the same. Saturated fatty acids have been linked to an increase in inflammatory serum markers (such as C-reactive protein) indicating an increased cardiovascular risk. It does not appear that all saturated fatty acids behave equally. In some studies [7] that investigated the effects of 4 saturated fatty acids (lauric, myristic, palmitic and stearic) and the relationship between total saturated fat and polyunsaturated fat in terms of blood concentrations of highly sensitive C-reactive protein, adiponectin and leptin, it was found that there was a detrimental role of lauric and myristic saturated fatty acids and a high ratio of saturated fat and polyunsaturated fat to C-reactive protein levels.

Almost none of the recommendations of international bodies make a distinction between different saturated fatty acids perhaps because their predominant sources are the same foods [8].

\section{Substitution of saturated fat by other alternatives?}

FAO/WHO [8] has established that there is convincing evidence that the substitution of saturated fatty acids by polyunsaturated fatty acids decreases the concentration of LDL-cholesterol and the total cholesterol ratio: HDL cholesterol. The same with monounsaturated fatty acids decreases but to a lesser extent.
The substitution of saturated fatty acids by carbohydrates decreases the concentration of LDL-cholesterol, HDL-cholesterol but does not change the total cholesterol ratio: HDL cholesterol.

\section{Interaction between fat and food matrix?}

Calcium can be an example that the effects of saturated fatty acids in cardiovascular disease or cardiovascular risk are modulated by certain nutrients and therefore will depend on the matrix in which they are on the margin that not all saturated fatty acids behave equally.

Some studies [9] compared diets with semi-skimmed milk or semi-skimmed cheese with a non-dairy control diet and found that they produced an increase in total cholesterol and LDL cholesterol, albeit attenuated (not as much as might be expected in principle).

Certain studies [9] compared diets with semi-skimmed milk or semi-skimmed cheese with a non-dairy control diet and found that they produced an increase in total cholesterol and LDL cholesterol although attenuated (not as much as might be expected in principle) and it was observed that there was an increase in the excretion of faecal fat and that the effects of milk and cheese were similar.

It appears that some of the effects of dairy could be due to its calcium content (and not just the presence of specific saturated fatty acids). It has not been suggested in vain that calcium intake increases fecal excretion of fat and also helps to reduce body fat. It has been talked about for years that it is possible that during caloric restriction (when we ingest less energy than we spend) taking an adequate dose of calcium can help to lose body fat. In fact, there have been studies for years [10] that suggest that diets rich in calcium can help reduce body fat by increasing fat oxidation, increasing the thermogenic effect of foods, and reducing fat intake (by forming soaps and being eliminated by feces).

Calcium in the form of dairy products appears to be more effective than elemental calcium since other components present in serum may promote this action [11].

A meta-analysis published in 2009 concludes that calcium intake increases excretion of fat by faeces [12], a systematic review published in [13] 2011 concludes that calcium intake helps reduce body weight and fat, and a meta-analysis published in October 2012 concludes that calcium increases fat oxidation [14]. Less fat means less cardiovascular risk. 
Some studies conclude that the intake of 3 or more daily servings of dairy can help reduce weight and body fat $[15,16]$ and that an intake of $600 \mathrm{mg}$ of calcium appears to be a sufficient dose to achieve the reducing effect on adipose tissue, best with 125 IU of vitamin D. In fact, it is suggested that combining calcium with vitamin D can have a greater effect since vitamin D can increase calcium intake in the adipocyte [15].

Some studies suggest that dairy products may help to increase lean mass in addition to helping to lose body fat [17] so that we could achieve an extra physiological benefit (increased basal metabolic expenditure and better weight control for example).

Modification of the lipid profile of milk?

There have been strategies (such as modifying cattle feed) that aimed to modify the lipid profile of milk by increasing its richness in conjugated linoleic acid and even in omega-3 fatty acids (DHA and EPA) to obtain a final product whose habitual consumption could offer a series of advantages from the point of view of cardiovascular health [18] although it is true that there is growing evidence [19] that saturated fatty acids in the context of dairy products (and especially in fermented dairy products) have neutral or inverse associations with cardiovascular disease. It may be that the problem is not so much saturated fat as excess carbohydrates when saturated fat is replaced by them. It appears that [20] replacing saturated fat with polyunsaturated or monounsaturated fat may reduce the risk of cardiovascular disease but when replaced by carbohydrates (namely simple sugars such as sucrose) there may even be an increased risk of cardiovascular disease. And it is that we cannot think about denigrating carbohydrates that are added instead of fats because many of the studies do not compare saturated fats and different types of carbohydrates in relation to the risk of heart disease, i.e. perhaps many people by reducing saturated fat increase the consumption of certain types of carbohydrates, refined sugars for example. Moreover, it is common to see in the market a wide variety of $0 \%$ fat or low fat products that nevertheless have a high amount of simple sugars, so it is not surprising that when choosing foods low in saturated fat are both rich in refined sugars.

So perhaps it is not so much that reducing saturated milk fat does not bring such significant benefits, probably this absence of benefits can occur when saturated fat is replaced by simple sugars which is the norm, because if saturated fat is replaced by whole grain, polyunsaturated fat or monounsaturated fat there are health benefits [20]. However, by replacing these saturated fats with other sources of carbohydrates, it is possible to replace them with whole grain, polyunsaturated fat or monounsaturated fat [20].

However, the substitution of these saturated fats by other carbohydrate sources (other than simple sugars) such as fruits, vegetables, whole grains... obviously they are not expected to worsen and perhaps other additional physiological benefits can be obtained.

What all this seems to indicate is that a certain distribution of macronutrients is of little value, and what really matters is a hearthealthy diet rich in nuts (nuts, almonds...), fish, vegetables, fruits, legumes, whole grains and dairy products. With regard to dairy products, there are even systematic reviews and meta-analyses [21] which conclude that there is no consistent association between milk consumption and all-cause mortality or mortality from specific causes (cancer or cardiovascular disease).

Are all dairy products the same?

Evidence suggests that not all dairy products are the same and that fermented milks, such as yogurts, and especially non-fat free, are preferable in terms of cardiovascular, metabolic prevention and body weight control [22].

Is the cheese different?

Because cheese is richer in fat than most dairy products, and since it carries a significant amount of added salt that raises its sodium content, it has often been recommended to limit its consumption, however scientific evidence [23] suggests that its consumption is not only not harmful but it can be interesting from the cardiovascular and metabolic point of view.

\section{Purpose}

The objective of this study was a fresh cheese without salt, enzymatic coagulation and with addiction of the probiotics Lactobacillus casei and Lactobacillus acidophilus, raw unsalted nut, cinnamon, rosemary, oregano, oat betaglucan and sweet paprika in order to frequent consumption, a ratio of 130 grams per day, supposed, in healthy humans, a beneficial physiological effects.

Justification and background

There are no cheeses in the market that combine all the ingredients included in the cheese, not even several of them, although there are antecedents with good results in other products such as hamburgers [24]. The good results obtained in studies with other similarly modified foods and the fact that the ingredients added to 
the cheese are interesting [25-31] in themselves in terms of their physiological effects, suggest possible benefits derived from the regular consumption of this proposed cheese.

\section{Methods}

It was based on 86 volunteers of both sexes, healthy and overweight, between 18 and 50 years. Among the 86 volunteers a random selection was made and the study began with a duration of 6 weeks. The sample consisted of two groups of 15 patients each. Groups participating in study

- $\quad$ Experience Group: Modified Cheese Intake

\section{- Control group: I would eat a normal cheese}

It was assessed whether there were statistically significant results between the beginning and at 6 weeks in each of the variables measured in the two groups.

The variables analyzed were these

C-reactive protein ultrasensitive, defecation frequency, glycosylated hemoglobin, triglycerides, LDL cholesterol, body fat percentage.

Composition of experimental groups

\begin{tabular}{|l|c|c|c|}
\hline Type of cheese & Sex & $\begin{array}{c}\text { Number of } \\
\text { individuals }\end{array}$ & Percentage \\
\hline \multirow{2}{*}{ Modified cheese } & Male & 5 & 33,3 \\
\cline { 2 - 4 } & Female & 10 & 66,7 \\
\hline \multirow{2}{*}{ Normal cheese } & Male & 6 & 40,0 \\
\cline { 2 - 4 } & Female & 9 & 60,0 \\
\hline
\end{tabular}

Table 1

\section{Results}

C-reactive protein ultrasensitive, it does not fit the normal distribution; The comparative tests that were used were non-parametric.

The average value of the C-reactive protein increased in the spiced cheese group and decreased in the white cheese group at the final moment with respect to the initial one.

\begin{tabular}{|c|c|c|c|c|c|c|}
\hline \multicolumn{2}{|c|}{ Type of cheese } & $\mathbf{n}$ & Media & $\begin{array}{c}\text { Standard } \\
\text { deviation }\end{array}$ & $\begin{array}{c}\text { Mini- } \\
\text { mum }\end{array}$ & $\begin{array}{c}\text { Maxi- } \\
\text { mum }\end{array}$ \\
\hline \multirow{2}{*}{$\begin{array}{c}\text { Modi- } \\
\text { fied } \\
\text { cheese }\end{array}$} & Initial & 15 & 2,2133 & 2,6574 &, 25 & 10,35 \\
\cline { 2 - 7 } & Final & 15 & 2,7760 & 3,9544 &, 18 & 15,88 \\
\hline $\begin{array}{c}\text { Normal } \\
\text { cheese }\end{array}$ & Initial & 15 & 2,2960 & 2,5426 &, 15 & 10,39 \\
\cline { 2 - 7 } & Final & 15 & 1,7093 & 1,6864 &, 23 & 6,79 \\
\hline
\end{tabular}

Table 2
But, according to the results of the Wilcoxon signed ranges test, they are not statistically significant results.

\begin{tabular}{|l|c|}
\hline Type of cheese & Symptotic significance, bilateral \\
\hline Modified cheese &, 955 \\
\hline Normal cheese &, 233 \\
\hline
\end{tabular}

Table 3

\section{Defecatory frequency}

The variable did not present a normal distribution, so a nonparametric comparison test was used.

\begin{tabular}{|c|c|c|c|c|c|c|}
\hline \multicolumn{2}{|c|}{ Type of cheese } & $\mathbf{n}$ & Mean & $\begin{array}{c}\text { Typical } \\
\text { deviation }\end{array}$ & $\begin{array}{c}\text { Mini- } \\
\text { mum }\end{array}$ & $\begin{array}{c}\text { Maxi- } \\
\text { mum }\end{array}$ \\
\hline \multirow{2}{*}{ Spicy } & Initial & 15 & 1,27 &, 594 & 1 & 3 \\
\cline { 2 - 7 } & Final & 15 & 1,87 &, 990 & 1 & 4 \\
\hline \multirow{2}{*}{ White } & Initial & 15 & 1,73 & 1,033 & 1 & 4 \\
\cline { 2 - 7 } & Final & 15 & 1,47 &, 640 & 1 & 3 \\
\hline
\end{tabular}

Table 4

Defecation rate, results of the Wilcoxon signed ranges test:

There are statistically significant results, it can be affirmed that the increase in defecation frequency was due to the consumption of spiced cheese.

\begin{tabular}{|l|c|}
\hline Type of cheese & Sig. asintót. (bilateral) \\
\hline Spicy &, 007 \\
\hline White &, 102 \\
\hline
\end{tabular}

Table 5

Glycosylated haemoglobin

The comparative tests that were used were non-parametric.

Glycosylated hemoglobin behavior for each type of initial and final cheese

\begin{tabular}{|l|c|c|c|c|c|c|}
\hline \multicolumn{2}{|c|}{ Type of cheese } & $\mathbf{n}$ & Media & $\begin{array}{c}\text { Typical } \\
\text { deviation }\end{array}$ & $\begin{array}{c}\text { Mini- } \\
\text { mum }\end{array}$ & $\begin{array}{c}\text { Maxi- } \\
\text { mum }\end{array}$ \\
\hline \multirow{2}{*}{ Spicy } & Initial & 15 & 5,36 &, 49 & 4,70 & 6,80 \\
\cline { 2 - 7 } & Final & 15 & 5,1467 &, 5208 & 4,40 & 6,60 \\
\hline \multirow{2}{*}{ White } & Initial & 15 & 5,2200 &, 2756 & 4,60 & 5,60 \\
\cline { 2 - 7 } & Final & 15 & 5,2133 &, 2899 & 4,50 & 5,60 \\
\hline
\end{tabular}

Table 6 
Effect on Human Volunteers of a Fresh Cheese of Enzymatic Coagulation, with Probiotics and Vegetable Ingredients

Glycosylated haemoglobin, contrast test results

There are statistically significant results, it can be affirmed that the glycosylated hemoglobin decrease was due to the consumption of spiced cheese.

\begin{tabular}{|l|c|}
\hline Type of cheese & Sig. asintót. (bilateral) \\
\hline Spicy &, 006 \\
\hline White &, 794 \\
\hline
\end{tabular}

Table 7

\section{Triglycerides}

The variable did not show normal distribution for both experimental groups, therefore, non-parametric contrast tests were performed.

\begin{tabular}{|l|l|l|l|c|c|c|}
\hline \multicolumn{2}{|c|}{ Type of cheese } & n & Media & $\begin{array}{c}\text { Typical } \\
\text { deviation }\end{array}$ & $\begin{array}{c}\text { Mini- } \\
\text { mum }\end{array}$ & $\begin{array}{c}\text { Maxi- } \\
\text { mum }\end{array}$ \\
\hline \multirow{2}{*}{ Spicy } & Initial & 15 & 106,80 & 68,88 & 41 & 319 \\
\cline { 2 - 7 } & Final & 15 & 88,93 & 51,72 & 39 & 259 \\
\hline \multirow{2}{*}{ White } & Initial & 15 & 91,20 & 66,34 & 49 & 318 \\
\cline { 2 - 7 } & Final & 15 & 87,80 & 51,56 & 42 & 239 \\
\hline
\end{tabular}

Table 8

There are statistically significant results, it can be affirmed that the triglycerides decrease was due to the consumption of spiced cheese.

\begin{tabular}{|l|c|}
\hline Type of cheese & Sig. asintót. (bilateral) \\
\hline Spicy &, 010 \\
\hline White &, 955 \\
\hline
\end{tabular}

Table 9

\section{LDL-Cholesterol}

The variable did not show normal distribution for both experimental groups, therefore, non-parametric contrast tests were performed.

\begin{tabular}{|l|c|c|c|c|c|c|}
\hline \multicolumn{2}{|c|}{ Type of cheese } & $\mathbf{n}$ & Media & $\begin{array}{c}\text { Typical } \\
\text { deviation }\end{array}$ & $\begin{array}{c}\text { Mini- } \\
\text { mum }\end{array}$ & $\begin{array}{c}\text { Maxi- } \\
\text { mum }\end{array}$ \\
\hline \multirow{2}{*}{ Spicy } & Initial & 15 & 141,0467 & 30,0177 & 90,10 & 207,40 \\
\cline { 2 - 7 } & Final & 15 & 129,8133 & 26,4167 & 88,20 & 170,40 \\
\hline \multirow{2}{*}{ White } & Initial & 15 & 130,1733 & 26,6367 & 90,10 & 189,00 \\
\cline { 2 - 7 } & Final & 15 & 134,9667 & 41,9960 & 86,50 & 255,30 \\
\hline
\end{tabular}

There are statistically significant results, it can be affirmed that the LDL-Cholesterol decrease was due to the consumption of spiced cheese.

\begin{tabular}{|l|c|}
\hline Type of cheese & Sig. asintót. (bilateral) \\
\hline Spicy &, 010 \\
\hline White &, 307 \\
\hline
\end{tabular}

Table 11

\section{Body fat percentage}

The variable did not show normal distribution for both experimental groups, therefore, non-parametric contrast tests were performed.

\begin{tabular}{|l|l|l|l|c|c|}
\hline \multicolumn{2}{|c|}{ Type of cheese } & Media & n & $\begin{array}{c}\text { Deviation } \\
\text { typ. }\end{array}$ & $\begin{array}{c}\text { Fatal. } \\
\text { average }\end{array}$ \\
\hline Spicy & Initial & 34,7000 & 15 & 7,7393 & 1,99828 \\
\cline { 2 - 6 } & Final & 33,0667 & 15 & 7,8558 & 2,02836 \\
\hline \multirow{2}{*}{ White } & Initial & 31,2000 & 15 & 11,6729 & 3,01394 \\
\cline { 2 - 6 } & Final & 31,0533 & 15 & 11,6448 & 3,00669 \\
\hline
\end{tabular}

Table 12

There are statistically significant results, it can be affirmed that the body fat percentage decrease was due to the consumption of spiced cheese.

\begin{tabular}{|l|c|c|c|c|c|}
\hline \multirow{2}{*}{$\begin{array}{l}\text { Type of } \\
\text { cheese }\end{array}$} & \multicolumn{3}{|c|}{ Related differences } & \multirow{2}{*}{ T } & \multirow{2}{*}{$\begin{array}{c}\text { Sig. (bi- } \\
\text { lateral) }\end{array}$} \\
\cline { 2 - 5 } & Media & $\begin{array}{c}\text { Deviation } \\
\text { typ. }\end{array}$ & $\begin{array}{c}\text { Fatal. } \\
\text { average }\end{array}$ & &, 000 \\
\hline Spicy & 1,63333 & 1,28155 &, 33090 & 4,936 &, 600 \\
\hline White &, 14667 & 1,1963 &, 3088 &, 475 &, 642 \\
\hline
\end{tabular}

Table 13

\section{Discussion}

The results show how there is a significant reduction in LDLcholesterol, glycosylated hemoglobin, triglycerides and body fat percentage. It is difficult to be able to attribute these effects to a single ingredient, but it is probably the sum of their effects separately... in fact, several studies suggest positive effects, in these aspects, derived from the consumption of spices, due to their richness in phytonutrients such as polyphenols and others, of the consumption of betaglucan of oats, of the intake of probiotics and of the nut, which among other things is rich in short chain omega 3 fatty acids.

Table 10 
Regarding the ultrasensitive c-reactive protein, in principle one would expect a reduction derived from a higher consumption of antioxidants, but because it is a variable that can fluctuate greatly due to a multitude of situations such as infections, bumps, training etc... it may be This is the reason why there are no significant variations.

\section{Conclusions}

The SPECIFIED treatment has demonstrated a statistically significant effect on the reduction of LDL cholesterol, glycosylated hemoglobin, body fat percentage, defecation rate and triglycerides and has not demonstrated a statistically significant effect on the reduction of $\mathrm{C}$-reactive protein and cheese without added no has demonstrated a significant effect on any variable.

The logical statistical prudence would advise repeating the experiment with a larger sample number.

\section{Bibliography}

1. Hu FB., et al. "Dietary saturated fats and their food sources in relation to the risk of coronary heart disease in women". The American Journal of Clinical Nutrition 70 (1999): 1001-1008.

2. Hulshof KF., et al. "Intake of fatty acids in western Europe with emphasis on trans fatty acids: the TRANSFAIR Study". European Journal of Clinical Nutrition 53 (1999): 143-157.

3. Chowdhury R., et al. "Association of dietary, circulating, and supplement fatty acids with coronary risk: a systematic review and meta-analysis". Annals of Internal Medicine 160 (2014): 398-406.

4. Ettinger G., et al. "The influence of the human microbiome and probiotics on cardiovascular health". Gut Microbes 5 (2014): 719-728.

5. Thorning TK., et al. "Diets with high-fat cheese, high-fat meat, or carbohydrate on cardiovascular risk markers in overweight postmenopausal women: a randomized crossover trial". The American Journal of Clinical Nutrition (2015): pii: ajcn109116.

6. Drehmer M., et al. "Total and Full-Fat, but Not Low-Fat, Dairy Product Intakes are Inversely Associated with Metabolic Syndrome in Adults". Journal of Nutrition (2016): pii: jn220699.

7. Santos S., et al. "Saturated fatty acids intake in relation to Creactive protein, adiponectin, and leptin: a population-based study". Nutrition 29 (2013): 892-897.
8. FAO. "Fats and fatty acids in human nutrition Report of an expert consultation" (2010): 1-166.

9. Soerensen KV., et al. "Effect of dairy calcium from cheese and milk on fecal fat excretion, blood lipids, and appetite in young men". The American Journal of Clinical Nutrition 99 (2014): 984-991.

10. Zemel MB. "Proposed role of calcium and dairy food components in weight management and metabolic health". The Physician and Sportsmedicine 37 (2009): 29-39.

11. Zemel MB. "Role of calcium and dairy products in energy partitioning and weight management". The American Journal of Clinical Nutrition 79 (2004): 907S-912S.

12. Christensen R., et al. "Effect of calcium from dairy and dietary supplements on faecal fat excretion: a meta-analysis of randomized controlled trials". Obesity Reviews 10 (2009): 475486.

13. Onakpoya IJ., et al. "Efficacy of calcium supplementation for management of overweight and obesity: systematic review of randomized clinical trials". Nutrition Review 69 (2011): 335343.

14. Gonzalez JT., et al. "Effect of calcium intake on fat oxidation in adults: a meta-analysis of randomized, controlled trials". Obesity Reviews 13 (2012): 848-857.

15. Ping-Delfos WC and Soares M. "Diet induced thermogenesis, fat oxidation and food intake following sequential meals: influence of calcium and vitamin D". Clinical Nutrition 30 (2011): 376-383.

16. Chen M., et al. "Effects of dairy intake on body weight and fat: a meta-analysis of randomized controlled trials". The American Journal of Clinical Nutrition 96 (2012): 735-747.

17. Hlavatá K. "Calcium, dairy products and weight reduction". Casopis Lékaru Ceských 153 (2014): 238-241.

18. Lock AL and Bauman DE. "Modifying milk fat composition of dairy cows to enhance fatty acids beneficial to human health". Lipids 39 (2004): 1197-206.

19. Siri-Tarino PW., et al. "Saturated Fats Versus Polyunsaturated Fats Versus Carbohydrates for Cardiovascular Disease Prevention and Treatment". Annual Review of Nutrition 35 (2015): 517-543. 
20. Li Y., et al. "Saturated Fats Compared With Unsaturated Fats and Sources of Carbohydrates in Relation to Risk of Coronary Heart Disease: A Prospective Cohort Study". Journal of the American College of Cardiology 66 (2015): 1538-1548.

21. Larsson SC., et al. "Milk Consumption and Mortality from All Causes, Cardiovascular Disease, and Cancer: A Systematic Review and Meta-Analysis". It's Nutrients 7 (2015): 7749-7763.

22. Babio N., et al. "Consumption of Yogurt, Low-Fat Milk, and Other Low-Fat Dairy Products Is Associated with Lower Risk of Metabolic Syndrome Incidence in an Elderly Mediterranean Population". Journal of Nutrition 145 (2015): 2308-2316.

23. Chen GC., et al. "Cheese consumption and risk of cardiovascular disease: a meta-analysis of prospective studies". European Journal of Nutrition 56 (2017): 2565-2575.

24. De Cangas R., et al. "Design of a chicken burger, with added plant elements, with various health benefits". Nutrición Clínica y Dietética Hospitalaria 38 (2018): 44.

25. Hariri M and Ghiasvand R. "Cinnamon and Chronic Diseases". Advances in Experimental Medicine and Biology 929 (2016): $1-24$.

26. Naimi M., et al. "Rosemary Extract as a Potential Anti-Hyperglycemic Agent: Current Evidence and Future Perspectives". Nutrients 9 (2017).

27. Veenstra JP and Johnson JJ. "Oregano (Origanum vulgare) extract for food preservation and improvement in gastrointestinal health". International Journal of Nutrition 3 (2019): 43-52.

28. Varghese S., et al. "Chili pepper as a body weight-loss food". International Journal of Food Sciences and Nutrition 68 (2017): 392-401.

29. Ferguson JJ., et al. "High molecular weight oat $\beta$-glucan enhances lipid-lowering effects of phytosterols. A randomised controlled trial". Clinical Nutrition 10 (2019): pii: S02615614(19)30059-7.
30. Shimizu M., et al. "Meta-Analysis: Effects of Probiotic Supplementation on Lipid Profiles in Normal to Mildly Hypercholesterolemic Individuals". PLoS One 10 (2015): e0139795.

31. de Souza RGM., et al. "Nuts and Human Health Outcomes: A Systematic Review". Nutrients 9 (2017).

\section{Volume 3 Issue 12 December 2019}

(C) All rights are reserved by Ramón De Cangas Morán and Aldo Hernández Monzón. 